\title{
An unexpected ECG finding
}

\author{
M.J. Kuiper · A.R. Willems · A.A.M. Wilde
}

Published online: 8 October 2015

(C) The Author(s) 2015. This article is published with open access at Springerlink.com

Fig. 1 ECG at presentation

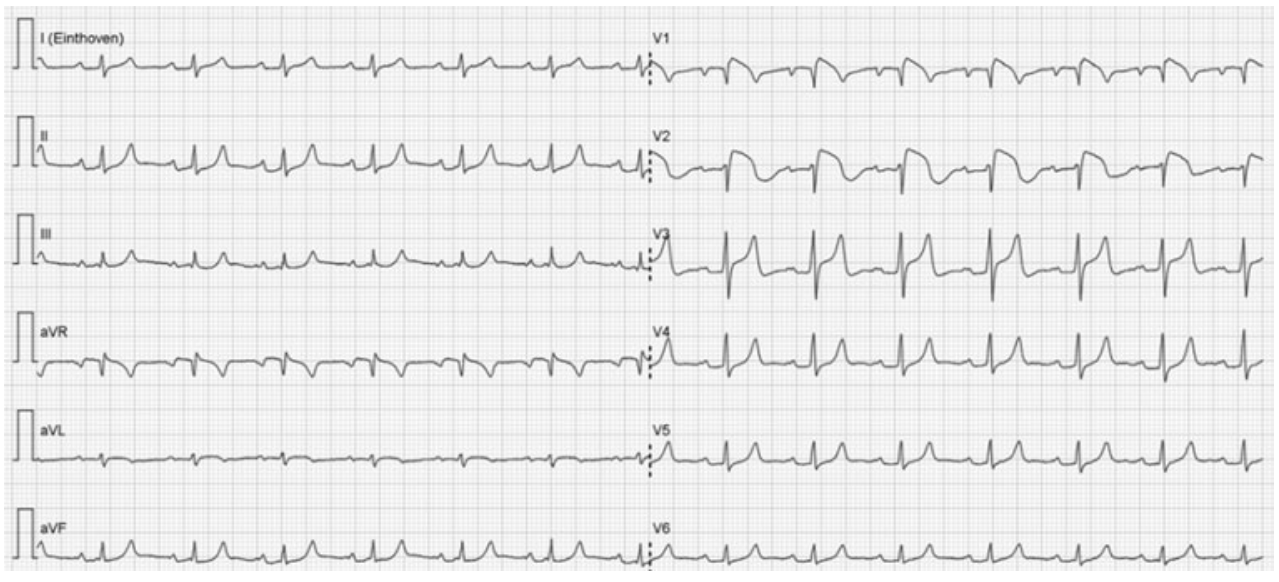

In this case we present a 51-year-old, female patient of Pakistani origin. Her medical history includes hepatitis $\mathrm{C}$ induced Child-Pugh B liver cirrhosis and she had recently been recently admitted to our hospital due to ascites with poor response to medical therapy. Currently the patient was

\section{M.J. Kuiper ( $₫)$}

Department of Cardiology, Haga Teaching Hospital,

The Hague, The Netherlands

e-mail: mathijskuiper@hotmail.com

\section{M.J. Kuiper}

Department of Internal Medicine, Sint Lucas Andreas Hospital,

Amsterdam, The Netherlands

\section{A.R. Willems}

Department of Cardiology, Sint Lucas Andreas Hospital, Amsterdam, The Netherlands

\section{A.A.M. Wilde}

Department of Cardiology, Academic Medical Centre,

Amsterdam, The Netherlands referred to our emergency department because of nausea and abdominal discomfort. She had no cardiac medical history and a low cardiovascular risk profile. Physical examination revealed dehydration and mild diffuse abdominal pain. The patient was not experiencing fever. The laboratory results mainly showed hyperkalaemia $(8.6 \mathrm{mmol} / \mathrm{l})$. The cardiology consultant was contacted after the ECG (Fig. 1) was taken.

What is your diagnosis?

\section{Answer}

You will find the answer elsewhere in this issue.

Open Access This article is distributed under the terms of the Creative Commons Attribution License which permits any use, distribution, and reproduction in any medium, provided the original author(s) and the source are credited. 